\title{
MORTALIDADE DAS MICRO E PEQUENAS EMPRESAS: UM OLHAR SOBRE A LEI №8.934/94
}

\section{ARTIGO ORIGINAL}

ARAÚJO, Jamille Carla Oliveira ${ }^{1}$

LIMA, Leila Simey Rodrigues ${ }^{2}$

GOUVEIA, Geraldo Adriano Ribeiro ${ }^{3}$

BARBOSA, Eldilene da Silva ${ }^{4}$

ARAÚJO, Jamille Carla Oliveira. Et al. Mortalidade das micro e pequenas empresas: um olhar sobre a lei n8.934/94. Revista Científica Multidisciplinar Núcleo Do Conhecimento. Ano 04, Ed. 10, Vol. 06, pp. 154-173. Outubro de 2019. ISSN: 2448-0959, Link de acesso: https://www.nucleodoconhecimento.com.br/contabilidade/mortalidade-dasmicro

\section{RESUMO}

Tem-se como objetivo investigar as principais causas do surgimento de empresas canceladas na cidade de Capanema Pará por meio de uma análise in locu dos arquivos da Junta Comercial do Estado do Pará (JUCEPA). Para a análise dos dados,

\footnotetext{
${ }^{1}$ Mestre em Administração, MBA Gestão contábil, perícia, auditoria e controlaria, Bacharel em Ciências Contábeis.

2 Discente do curso de Ciências Contábeis da Universidade Federal Rural da Amazônia (UFRA).

${ }^{3}$ Discente em Bacharel em Direito UNAMA, MBA logistica, Bacharel em Ciências Contábeis, Servidor Público da Junta Comercial do Estado do Pará.

${ }^{4}$ Mestre em Administração, MBA Gestão contábil, perícia, auditoria e controlaria, Bacharel em Ciências Contábeis.
} 
aplicou-se um questionário a empreendedores que se encontram com suas empresas com status de cancelada. A partir dessas informações, analisou-se as principais causas de cancelamento destas MPEs do município de Capanema/PA, entre os anos de 2014 e 2017. Para tanto, foi utilizado o método qualitativo e descritivo, no qual os dados foram organizados, descritos e analisados por meio de tabelas de frequências. Conclui-se que os fatores ligados ao cancelamento empresarial não estão ligados a um fator isolado, mas a um conjunto de fatores internos e externos, sendo os fatores relacionados ao ambiente externo os principais causadores do cancelamento de seus negócios.

Palavras-chave: Empreendedorismo, cancelamento, MPEs.

\section{INTRODUÇÃO}

Couto et al (2017) entendem que o empreendedorismo está, intimamente, relacionado com o desenvolvimento nos âmbitos econômico, tecnológico e social de qualquer nação. É uma realidade presente, também, em nosso país. O Brasil, no ano de 2014, atingiu o seu ápice na Taxa Total de Empreendedores (TTE). Assim sendo, alcançou $34,5 \%$ da população adulta com faixa etária entre 18 e 64 anos. Pode-se, então, reiterar que a cada 3 brasileiros adultos, pelo menos 1 já possuiu um negócio ou esteve envolvido no processo de criação de algum negócio. É de conhecimento geral que, ao longo dos anos, assim como aumenta o número de novos de empreendimentos, também se aumenta o número de empresários que não estão em dúvida sobre como manter seu negócio e optam pela paralisação de suas atividades, de caráter informal (SEBRAE, 2015).

No mundo moderno sempre houveram estudos voltados para as causas de mortalidade de MPEs no Brasil (ALBUQUERQUE; ESCRIVÃO FILHO, 2011; ALBUQUERQUE, 2013). Outros estudos se voltaram a compreender quais os motivos pelos quais a falência das MPEs assola os brasileiros. Para tanto, segue-se as diretrizes do princípio de sustentabilidade empresarial (LEZANA; GRAPEGGIA, 2006, COUTO et. al. 2017). Entretanto, nenhum outro estudo efetuou uma abordagem sobre as empresas que se encontram canceladas, ou seja, não foi tomada a decisão de 
extinguir, de reativar, e nem de paralisar a organização, ficando a mesma com o CNPJ e computando tributação caso não tenha feito declarações de sem movimentação.

Destarte, a partir da leitura de materiais empíricos que caminharam em busca da compreensão das causas mais recorrentes que fazem com que as MPEs sejam canceladas nos municípios brasileiros encontrou-se a justificativa para a proposição deste estudo. A presente pesquisa pretende fornecer informações pertinentes de forma a contribuir para com a elaboração de estratégias que podem auxiliar na amenização da omissão ou a falta de informação para os MPEs, auxiliando este empresários a diferenciar as situações de cancelada, extinto, reativado, paralisado, com o propósito as consequências destes atos, assim como elencar a importância das empresas na atual conjuntura como fonte de emprego e de renda.

Desta forma, a relevância se dá por ser um estudo pioneiro se traduz através da influência do cancelamento de empresas na mortalidade das empresas, reativação ou paralização de organizações. É um estudo pertinente pois, segundo Ribeiro, Freire e Barella (2012), esse fenômeno faz com que a prática do cancelamento se torne recorrente. Assim, o estudo pretende contribuir no processo de tomada de decisões de empresários, visando, sobretudo, que esses adiram a concepções mais abrangentes sobre os impactos de eventos temporais diversos (considerando, então, passado, presente e futuro) para que, assim, sejam capazes de aderir novas posturas ao tomar decisões deste tipo.

As ações que envolvem o ato de cancelar se molda no propósito gerenciamento de informações e dados, estabelecendo o papel da contabilidade como fornecedora de informação e difusora da qualidade das mesmas, mas também efetuando conjuntamente uma reflexão da realidade empresarial. O objetivo deste estudo é identificar as principais causas do surgimento de empresas canceladas na cidade de Capanema Pará. Parte-se da hipótese de que esse fato é motivo das principais causas do cancelamento de empresas na cidade, referenciando, neste contexto, a importância do assessoramento por parte dos profissionais das ciências contábeis para orientar estes empresários na tomada de decisão, direcionando-os, sobretudo, para a decisão de extinguir, paralisar ou reativar uma organização. 
Pretende-se trazer para a discussão fontes científicas diversas sobre empresários que se encontram nesta situação perante a JUCEPA, Receita Federal do Brasil (RFB) e Secretaria da Fazenda Estadual (SEFA) (CATELLI, 2001, PORTER, 2008, PADOVEZE, 2009, 2015), visto que a definição do próximo passo da decisão de sair do status cancelada deve considerar o contexto mercadológico e empresarial (LEUZ, WYSOCKI, 2008). Para se alcançar esta pesquisa, buscou-se saber: quais as principais causas do surgimento de empresas canceladas no município de Capanema Pará.

\section{REFERENCIAL TEÓRICO}

\section{O EMPREENDEDORISMO E O EMPREENDEDOR}

O empreendedorismo é uma estratégia que contribui, diretamente, para que seja possível atingir o sucesso empresarial. O Sebrae (2017), defende que o empreendedor, de forma geral, deve ser motivado pela auto realização bem como pelo desejo de ser responsável e independente. São características primordiais. Esse contexto não pode ser compreendido universalmente, pois existem diversos estudos sobre o empreendedorismo que tratam como uma oportunidade de criação, ou seja, de negócio, envolvendo neste processo um conjunto de descobertas, exploração e avaliação de atividades envolvidas (Shane e Venkataraman, 2000).

Para Dornelas (2008), o empreendedorismo trata-se de oportunidades e de inovação de negócio. Assim, deve ser capaz de empregar as mais diversas ferramentas disponíveis para, de forma criativa, assumir riscos. Não se pode, entretanto, esquecer de trabalhar com os objetivos estabelecidos de forma clara. Destarte, ser empreendedor é o mesmo que ser capaz de produzir e colocar em prática novas ideias por meio da interação entre a criatividade e a imaginação. Considera-se como características inerentes ao empreendedor a auto avaliação, a autocrítica e o controle do comportamento para o autodesenvolvimento (SEBRAE, 2017; COUTO et al, 2017). 


\section{O CONCEITO DE MPE}

O conceito de MPE não é universal e os seus padrões de caraterização e classificação se distinguem entre os países e os setores responsáveis pela regulamentação (COUTO et. al., 2017). A partir da Lei Complementar (LC) ํo 123, de 14 de dezembro de 2006, que institui o Estatuto Nacional da Microempresa e da Empresa de Pequeno Porte, define-se, em seu artigo $3^{\circ}$, que o tamanho das empresas está relacionado com o seu faturamento anual. Entretanto com a Lei Complementar no 128 de 19 de dezembro de 2008 e a Lei Complementar no 155 de 27 de outubro de 2016, alteram o estatuto de micro e pequenas empresas para reorganizar e simplificar a metodologia de apuração do imposto devido por optantes pelo Simples Nacional (COUTO et al, 2017). As Juntas Comerciais acionam essas leis como uma possibilidade de enquadramento da Microempresa (ME) ou Empresa de Pequeno Porte (EPP), atendose, esta opção, pelo empresário ou contador, o qual informará seu porte empresarial por meio do seu faturamento no processo de constituição, alteração ou em ato de adequação de porte. Portanto, não possui um sistema de classificação arbitrário

\section{CANCELAMENTO ART. 60 DA LEI №8.934/94}

O cancelamento empresarial se procede, de acordo com o art. 60 da Lei oㅡ 8.9134/94, a partir da identificação da firma individual ou quando a sociedade não procede a qualquer arquivamento no período de dez anos consecutivos. Assim, deverá comunicar à junta comercial que deseja manter-se em funcionamento. Todas as empresas que possuem este tempo sem funcionamento ou movimentação deverão ser canceladas e seu cancelamento é efetivado com a sua publicação em diário oficial. O cancelamento apenas efetiva a informação de movimentação, portanto, não está eximido de quaisquer lançamentos tributários, e, dessa forma, mantém-se o número do Cadastro Nacional de Pessoa Jurídica (CNPJ), perdendo-se, entretanto, a proteção do nome pessoa jurídica. Portanto, decretado o cancelamento, a empresa deverá informar sua pretensão de extinguir, reativar ou paralisar a organização.

Para os atos de extinção e reativação o, o governo tem fornecido um desconto de $90 \%$ na taxa das Juntas Comerciais para efetiva definição dos empresários. No caso de 
paralisação, não se possui desconto em taxa, mas esta é utilizada para confirmar paralisação e evitar lançamentos tributários no período de paralisação. No Brasil, são muitos os estudos sobre a mortalidade empresarial, entretanto, no contexto da pesquisa, avaliou-se que existem 5 motivos de fracasso de empreendimentos utilizados por Pereira (1995). Podem ser utilizados para o cancelamento empresarial, dado que o cancelamento pode ser considerado uma primeira etapa da falência empresarial.

Quadro 1 - Motivos que levam ao fracasso de novos empreendimentos

\begin{tabular}{|l|l|}
\hline \multicolumn{1}{|c|}{ GRUPO } & \multicolumn{1}{c|}{ MOTIVOS } \\
\hline Aspectos técnicos & $\begin{array}{l}\text { Falta de experiência empresarial anterior. } \\
\text { Falta de competência gerencial. }\end{array}$ \\
\hline \multirow{2}{*}{ Área mercadológica } & $\begin{array}{l}\text { Desconhecimento do mercado. } \\
\text { Desconhecimento do produto ou serviço. }\end{array}$ \\
\hline \multirow{3}{*}{ Área técnico-operacional } & $\begin{array}{l}\text { Falta de qualidade nos produtos/serviços. } \\
\text { Localização errada. }\end{array}$ \\
& $\begin{array}{l}\text { Problemas na relação com fornecedores. } \\
\text { Tecnologia de produção obsoleta. }\end{array}$ \\
\hline \multirow{2}{*}{ Área financeira } & $\begin{array}{l}\text { Imobilização excessiva do capital em ativos fixos. } \\
\text { Política equivocada de crédito aos clientes. }\end{array}$ \\
\hline \multirow{2}{*}{ Área jurídica-organizacional } & Falta de controle de custos e de gestão financeira. \\
\hline & Estrutura organizacional concentrada. \\
& Falta de um sistema de planejamento e de informações gerenciais. \\
& Ausência de inovações gerenciais. \\
\hline
\end{tabular}

Fonte: Adaptado de Pereira (1995).

O quadro 1 reflete os motivos de fracasso empresarial que contribuem tanto para o fracasso empresarial, como, também, para o cancelamento da empresa, pois a falta de motivação pode trazer o desinteresse em continuar com o empreendimento.

\section{PARALISAÇÃO TEMPORÁRIA}

Segundo a Instrução normativa ํo 72, de 28 de Dezembro de 1998, a paralisação temporária de suas atividades é o período no qual o empresário não promove o cancelamento dos seus registros ou, ainda, a perda da proteção do nome empresarial. Contudo, é preciso respeitar o prazo de 10 anos. Este período implica no cancelamento. A Junta Comercial, por sua vez, é responsável pela criação de um arquivo independente que deve conter os prontuários inerentes à empresa que teve os seus registros paralisados. Deve-se, então, manter atualizado o Cadastro Estadual de Empresas Mercantis. Este pode promover o recadastramento das empresas nele 
registradas. Para isso, é preciso de um arquivamento do ato de alteração do empresário individual e de empresa individual de responsabilidade Itda, de sociedade empresária e de cooperativa, observando a natureza do Registro Público de Empresas Mercantis e Atividades Afins.

\section{EXTINÇÃO}

Segundo a AATR-BA (2003), uma empresa pode ser considerada como extinta quando ela encerra as suas atividades parcial ou totalmente. Dentre os motivos possíveis para a sua extinção estão: se a empresa cessar as suas atividades, por morte do empregador; a empresa cessar suas atividades em virtude de atos do Governo ou promulgação de Lei; a empresa cessar suas atividades por motivo de força maior e a extinção da empresa provocada por motivo de força maior. Assim sendo, essa extinção pode ser definida como um conjunto de atos que visam à extinção da pessoa jurídica. Dessa forma, quando a dissolução é efetivada, entra-se, automaticamente, em um período de liquidação. Nessa fase são levantados os valores que compõem o patrimônio ativo e passivo de uma sociedade.

Paga-se, então, as dívidas e finaliza-se o procedimento com a partilha do resultado líquido final. Se esse for positivo, será distribuído entre os sócios conforme o estabelecido pelo contrato social (AATR-BA). Normalmente, a divisão é feita por meio de um procedimento proporcional de suas cotas de capital. A critério dos sócios, pode se efetivar em proporções diferentes. Nesse sentido, avalia-se que uma vez bemsucedida a dissolução, a pessoa jurídica deixa de existir em relação às operações normais, entretanto, continua a ser acionada com a finalidade de concretizar a liquidação e a partilha do acervo patrimonial. Assim, Filardi (2006) reitera que os principais fatores para que ocorra a extinção, ao qual denomina de "mortalidade", são os que aparecem no quadro de número 2 abaixo. 
Quadro 2 - Classificação dos fatores contribuintes para a mortalidade

\begin{tabular}{|l|l|l|}
\hline \multicolumn{1}{|c|}{ EMPREENDEDOR } & \multicolumn{1}{|c|}{ NEGÓCIO } & \multicolumn{1}{c|}{ AMBIENTE EXTERNO } \\
\hline Competência na gestão & Acesso ao crédito; & Burocracia legal e fiscal; \\
empresarial; & Mão de obra qualificada; & Competição dos concorrentes; \\
Experiência no ramo; & Planejamento estratégico; & Demanda dos clientes; \\
Nível de Escolaridade; & Suporte jurídico e contábil; & Fornecedores, representantes, \\
Profissionalização da relação com & Qualidade produtos/serviços; & distribuidores e parceiros; \\
sócios. & Inovação produtos/serviços. & Carga de impostos e tributos; \\
& & Aspectos econômicos, políticos, \\
& & tecnológicos, sociais e ambientais. \\
\hline
\end{tabular}

Fonte: Filardi (2006).

Outros estudos (Pereira, 1995, Couto et. al., 2017) empíricos também foram realizados por instituições brasileiras como SEBRAE e o Instituto Brasileiro de Planejamento Tributário (IBPT), visando identificar quais as principais causas para o encerramento das MPEs no país. Desta forma, confrontaram-se em três campos de análise que são: planejamento prévio, gestão empresarial e comportamento empreendedor. Com intuito de identificar as principais causas de acordo com SEBRAE e o IBPT, da redução das MPES, a pesquisa considerou o perfil das extintas empresas que se encontram canceladas.

\begin{tabular}{|c|c|c|}
\hline IBPT (2013) & & SEBRAE (2014b) \\
\hline $\begin{array}{l}\text { Falta de planejamento e informações de } \\
\text { mercado. }\end{array}$ & \multirow{4}{*}{$\begin{array}{l}\text { Planejamento } \\
\text { Prévio }\end{array}$} & \multirow{4}{*}{$\begin{array}{l}\text { Não levantamento de informações } \\
\text { importantes sobre o mercado; } \\
\text { Não realização do planejamento de itens } \\
\text { básicos antes do início das atividades; } \\
\text { Curto tempo de planejamento prévio. }\end{array}$} \\
\hline Complexidade tributária e burocracias. & & \\
\hline $\begin{array}{l}\text { Dificuldade de acesso ao crédito financeiro e } \\
\text { investimentos. }\end{array}$ & & \\
\hline $\begin{array}{l}\text { Tecnologias de gestão complexas e de alto } \\
\text { custo. }\end{array}$ & & \\
\hline Brigas familiares ou de sócios. & & Diminuta frequência de aperfeiçoamento de \\
\hline Falência. & $\begin{array}{l}\text { Gestão } \\
\text { Empresarial }\end{array}$ & $\begin{array}{l}\text { produtos e serviços, inovando em processos, } \\
\text { procedimentos, tecnologias e capacitação; } \\
\text { Experiência prévia ou conhecimento do } \\
\text { ramo; } \\
\text { Estratégias de diferenciação. }\end{array}$ \\
\hline $\begin{array}{l}\text { Encerramento espontâneo de atividades } \\
\text { (doença, morte, falta de estímulo á manutenção } \\
\text { do negócio). }\end{array}$ & Comportamento & $\begin{array}{l}\text { Não se antecipar aos fatos, buscar } \\
\text { informações e persistir nos objetivos; } \\
\text { Plano de ações para atingir metas e }\end{array}$ \\
\hline $\begin{array}{l}\text { Outras causas (desatualização tecnológica, } \\
\text { política econômica, etc.). }\end{array}$ & & $\begin{array}{l}\text { objetivos; } \\
\text { Contato com outras empresas, bancos, } \\
\text { entidades e o governo. }\end{array}$ \\
\hline
\end{tabular}

Fonte: Adaptado de IBPT (2013) e SEBRAE (2014b).

No planejamento prévio, é possível observar, conforme os dados do Instituto Brasileiro de Planejamento Tributário (IBPT, 2013), que os principais motivadores para o 
desaparecimento das MPEs, voltam-se à falta de planejamento, de informações de mercado, de questões financeiras seguida de uma série de outras causas ligadas ao negócio. Nos estudos do SEBRAE (2014), investiga-se, de forma mais direta, às características do empreendedor. Atribuem responsabilidade a ele de maneira mais explícita, sobretudo em relação ao encerramento dos micros e pequenos negócios. Entende-se, também, que o planejamento é uma das principais fontes de organização e gerenciamento empresarial capaz de compelir atos de baixa empresarial.

$\mathrm{Na}$ Gestão empresarial, o IBPT vincula-se aos casos de falência e brigas familiares enquanto que para o SEBRAE à falta de estratégias e treinamento. Logo, marca a necessidade do aperfeiçoamento e conhecimento, enfatizando-se que devem estar interligados para garantir uma estratégia empresarial adequada a realidade da empresa e ao seu perfil para não anular os caminhos da tradição mais aperfeiçoa-los em prol de ganhos. No perfil do comportamento empreendedor, está vinculada a adaptação ao mercado tecnológico e empresarial atual. Destarte, nota-se que as principais causas de mortalidade encontradas no Brasil são diversas e variam de acordo os padrões do campo de análise da pesquisa, apesar de grande parte das vezes caírem na repetição ou complementação.

\section{REATIVAÇÃO}

A reativação empresarial trata-se de retomar as atividades empresariais, através de cumprindo o protocolo de ativação empresarial na Junta Comercial, ou seja, podemos dizer que a reativação consiste na resolução das pendências jurídicas e fiscais de uma empresa. Desta forma, ela pode se situar dentro da legalidade e executar novamente seus serviços (ARAÚJO; CRUZ, 2018). O processo reativação implica em questões burocráticas que em um primeiro momento podem até mesmo criar empecilhos ao empreendedor, os quais podem ser sanados através com a ajuda de um contador para a otimização da reativação de CNPJ. A reativação é realizada através de uma alteração de informações, que nada mais é que uma atualização de informações, as quais no processo de Rede Nacional para Simplificação do Registro e Localização de Empresas e Negócios (REDISIM). 
Este foi instituído pela Lei Complementar 123/2006 e pela 11.598/2007, com respaldo da Constituição, em seus artigos 146, III, D, artigo 170, IX e artigo 179, que dispõem sobre a garantia à livre iniciativa, assim como à proteção e apoio do Estado à empresa individual de responsabilidade limitada, à empresa de pequeno porte, à microempresa, microempresário e ao microempreendedor. Integrando assim por meio de de um sistema que tem por finalidade integrar os diversos processos legais que permeiam a vida de uma empresa (ARAÚJO; CRUZ, 2018). Esses processos são: registro, inscrição, alteração e baixa (extinção). Ressalta-se que as empresas que encontram -se com o CNPJ inativo e/ou suspenso, ou tenham a suspensão do CNPJ vinculada a dívida tributária não podem solicitar sua reativação.

\section{METODOLOGIA}

\section{SUJEITO DE PESQUISA}

Para isto o estudo se fundamentará na cidade de Capanema, que possui o maior quantitativo de empresas registradas na região do Caeté, contribuiu com $R \$ 2,4$ bilhões na geração de riqueza da economia paraense, o que correspondeu a 2,64\% do PIB do estado do Pará. Entre os setores econômicos que constituem o PIB da RI o de maior valor adicionado é o setor de Serviços, equivalente a $R \$ 1,7$ bilhões, $71,30 \%$ do indicador da região e 3,8\% do Pará, incorporando tanto as atividades da administração pública, incluído a esfera municipal, estadual e federal, como as Atividades de segmentos (REGIÃO INTEGRAÇÃO, 2015). 
Figura 1: Mapa do Estado do Pará região do Caeté

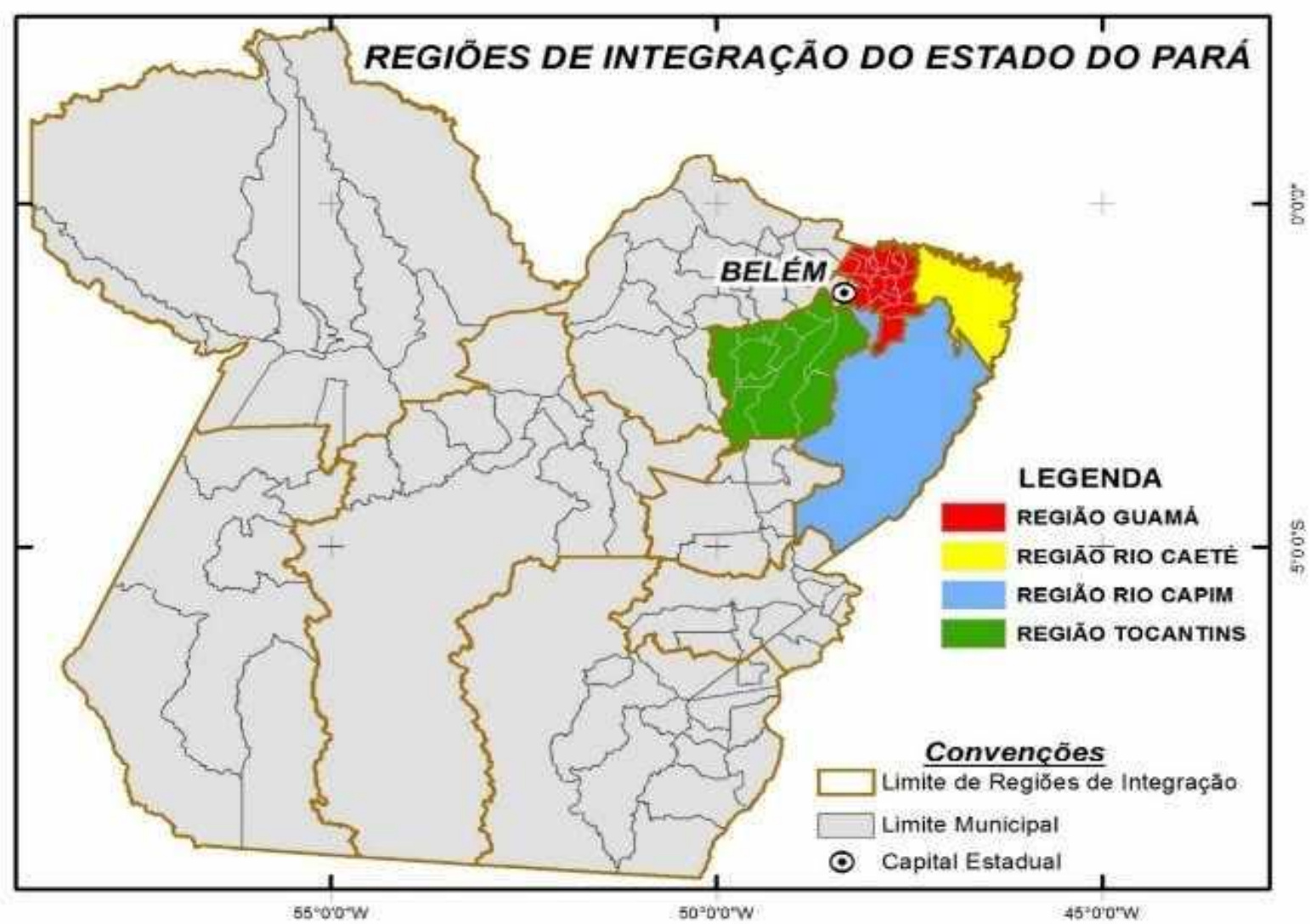

Fonte: Região Integração (2015).

Desta forma, um estudo minucioso identificou as necessidades e as dificuldades dos empresários, deixado claro ou trazido à tona para que esta não se torne enviesada, podendo, assim, causar danos em períodos posteriores, ratificando, portanto, a importância deste estudo para economia local e para os profissionais contábeis bem como a importância das informações contábeis independentemente de porte ou tamanho. São fenômenos essenciais para suportar o ambiente e para a tomada de decisão dos gestores (PADOVE, 2009, DIAS et. al. 2011; ARAÚJO; CRUZ, 2018; COUTO et al, 2017). Caracteriza-se como sujeito da pesquisa os micros e pequenos empreendedores do município de Capanema- Pa que se encontram com suas empresas com atividades com o status de cancelada na Junta Comercial do Estado de Pará (JUCEPA) entre os anos de 2014 e 2017. Para tanto, a identificação desses empreendedores deu-se por meio de um requerimento on-line das informações sobre 
as MPEs do município cadastradas no referido órgão e que encerraram as suas atividades no período identificado.

\section{PROCEDIMENTO DE PESQUISA}

O estudo se configura como uma pesquisa de caráter exploratório e descritivo. Isso possibilita compreender e detalhar o fluxo informações (GIL, 1995) a partir de uma perspectiva de entrada, processo e saída de informações referentes ao registro e computação de dados de inscrição, alteração, extinção, cancelamento e reativação (PADOVE, 2009, DIAS et. al. 2011). Isto, viabiliza a descrição do reflexo inerente à existência de empreendedores que tem deixado de ter seus próprios negócios. Desta forma, a pesquisa se encontra articulada em duas etapas de análise para a execução do trabalho, e, assim, está fundamentada no método de estudo por etapas de Silva (2003, p.39), que dispõe a investigação da verdade de modo ordenado com o propósito de atingir determinada finalidade e usar técnica como modo mais hábil, seguro e perfeito de alguma ação, arte, atividade e ofício (ARAÚJO; CRUZ, 2018).

A partir das recomendações feitas por Araújo e Cruz (2018), na primeira fase da pesquisa se classificou o quantitativo de empresas, depois o quantitativo de empresas canceladas e consequentemente extintas no período, os quais são a principal fonte de dados para obtenção da resposta desse estudo. Neste processo será obtido a lista com nome e endereço de empresas para se conseguir mapear as empresas e os empresários para aplicação da segunda etapa. Na segunda etapa trata-se da aplicação de questionário fechado e com perguntas abertas aos empresários, desenvolvidas de acordo com os estudos de Filardi (2006), Couto et. al. (2017) com o propósito de identificar as causas de desistência empresarial, e os motivos que o levaram a ficam sem movimentação empresarial por 10 anos e também por que não decidiu em reativar ou extinguir de vez a empresa.

Quadro 1: Questionário proposto

\section{Qual a principal atividade econômica dos entrevistados}

2 Sua empresa tinha funcionários? Sim, quantos? 
3 A empresa tinha definido os objetivos da empresa

4 A empresa fez um plano de negocio

5 O que pesou na decisão de parar com a empresa

6 Empresário, você tem a intenção de retornar com a organização?

Fonte: Elaborado pelos Autores, (2019).

Quanto ao tratamento e análise, os dados advindos do questionário serão organizados e distribuídos em planilhas do programa Microsoft Excel® de modo a possibilitar a análise das frequências e construção de gráficos e tabelas. O período compreendido para coleta dos dados foi entre os meses agosto a novembro do ano de 2018 e as análises e tratamento dos mesmos iram acontecer em novembro de 2018.

\section{RESULTADOS E DISCUSSÕES}

\section{ANÁLISE DA LONGEVIDADE EMPRESARIAL}

Durante a avaliação dos arquivamentos das empresas estas informações são importantes para no futuro se conseguir prever a tendência de longevidade empresarial, através da identificação das causas da existência das empresas sem movimentação por 10 anos (canceladas). Diante a isto, avalia-se a quantidade de empresas registradas no município de estudo.

Gráfico 1: Quantidade de empresas registradas, canceladas e extintas

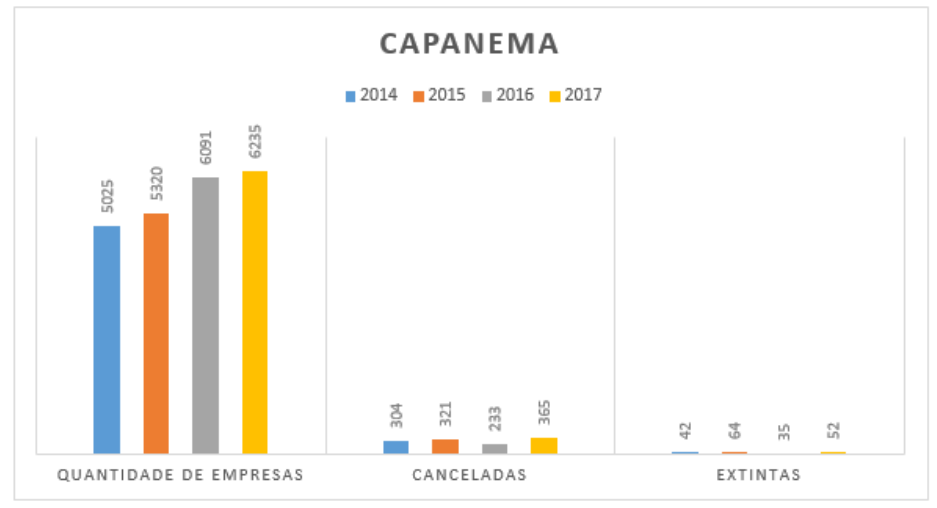

Fonte: Dados da Pesquisa, 2018. 
O gráfico 1 demonstra o crescimento do número de empresas no município de estudo, dado ao aumento do incentivo a legalização dos Microempreendedor Individual (MEI) e também da reativação de muitas empresas que estavam com o status de paralisadas por solicitação dos empresários, como foi possível constatar nos arquivos públicos (JUCEPA). Em relação as empresas canceladas notam-se que houve no ano de 2016 houve uma decisão de empresas efetuarem a reativação ao invés da extinção, prova disso houve uma redução no mesmo ano do quantitativo de empresas extintas. No gráfico 1 sobre a quantidade de empresas que constam com status de cancelada vem sofrendo alterações do ano de 2014 a 2015, aumentos, do ano 2015 a 2016 uma redução e 2016 a 2017 um novo aumento.

\section{ANÁLISE DAS CAUSAS DO SURGIMENTO DE EMPRESAS CANCELADAS}

A dificuldade de manter-se uma empresa, geri-la, administra-la vem de saber organizar as informações e também de saber seguir com foco os objetivos, visão, por mais que a tecnologia atual vem cada vez mais facilitando esse quesito (ARAÚJO; CRUZ, 2018). Para isto, identificar as formas de obtenção de receita torna-se um fator importante para saber se os gestores conseguem entender sua atividade desenvolvida. Desse modo, foi perguntado qual a atividade econômica da empresa. Segue a tabela 1.

Tabela 1: Sobre atividade econômica

Qual a principal atividade econômica dos entrevistados

\begin{tabular}{|l|l|l|}
\hline Especificações & Freq & \multicolumn{2}{l|}{} \\
\hline Vendas & 36 & $48 \%$ \\
\hline Serviços & 15 & $20 \%$ \\
\hline Vendas e serviços & 24 & $32 \%$ \\
\hline total & $\mathbf{7 5}$ & $\mathbf{1 0 0 \%}$ \\
\hline
\end{tabular}

Fonte: Elaborada pelas Autora. Questionário. 2019. 
Nota-se que dentre as atividades desenvolvidos pelos empresários que possuem suas atividades canceladas trabalham com vendas. Nesse contexto torna-se imprescritível para se obter eficácia na execução de um negócio avaliar o nível das informações repassadas aos gestores para o processo de tomada de decisão (PADOVEZE, 2015).Vale ressaltar que nos dias atuais a evolução da tecnologia da informação tem proporcionado uma melhoria contínua nesse aspecto através do desenvolvimento de sistemas de informações contábeis. Entretanto, independentemente da tecnologia não se supre a necessidade de possuir conhecimento de gestão empresarial (PADOVEZE, 2015). Analisando se a quantidade de funcionários poderia ter influência significativa no processo de cancelamento empresarial. Segue a tabela 2.

Tabela 2: Avaliação quantitativa de funcionários

Sua empresa tinha funcionários? Sim, quantos?

\begin{tabular}{|l|l|l|}
\hline Especificações & Freq & $\%$ \\
\hline SIM & 70 & $93 \%$ \\
\hline NÃO & 5 & $7 \%$ \\
\hline Total & $\mathbf{7 5}$ & $\mathbf{1 0 0 \%}$ \\
\hline Quantos? & & \\
\hline Especificações & Freq & $\%$ \\
\hline O a 5 funcionários & 51 & $68 \%$ \\
\hline $\mathbf{6}$ a 10 funcionários & 15 & $20 \%$ \\
\hline mais de 11 funcionários & $\mathbf{9}$ & $12 \%$ \\
\hline Total & $\mathbf{7 5}$ & $\mathbf{1 0 0 \%}$ \\
\hline
\end{tabular}

Fonte: Elaborada pelas Autora. Questionário. 2019.

Relacionar a quantidade de funcionários foi questionado para identificar se este fator tinha influência significativa. Entretanto, ao ouvir os empresários os mesmos colocaram que a carga dos encargos trabalhistas ainda é alta para os funcionários, e um dos principais problemas também foi a adequação aos sistemas para consequente folha de pagamento e o custo disso. Neste ponto as informações de uma organização e sua estrutura de vendas e serviços independentemente de porte ou tamanho, são 
essenciais para suportar o ambiente e para a tomada de decisão dos gestores (PADOVE, 2009, DIAS et. al. 2011). Dessa forma, avaliar se a organização tem objetivos definidos e/ou fez uso de um plano de negócio.

Tabela 3: Sobre plano de negócios versus objetivos

\begin{tabular}{|l|l|l|}
\hline A empresa tinha definido os objetivos da empresa & & \\
\hline Especificações & Freq & $\%$ \\
\hline SIM & 51 & $68 \%$ \\
\hline NÃO & 24 & $32 \%$ \\
\hline Total & $\mathbf{7 5}$ & $\mathbf{1 0 0 \%}$ \\
\hline A empresa fez um plano de negocio & Freq & \\
\hline SIM & 45 & $60 \%$ \\
\hline NÃO & 30 & $40 \%$ \\
\hline Total & $\mathbf{7 5}$ & $\mathbf{1 0 0} \%$ \\
\hline
\end{tabular}

Fonte: Elaborada pelas Autora. Questionário. 2019.

De acordo com Araújo e Cruz (2018), a análise da gestão financeira com a concepção de objetivos organizacionais bem definidos e tem um plano de negócio robusto, foi uma preocupação constatada em todas as empresas, entretanto, pouco deles tem a segurança necessária para administrar as informações e constatações das informações da sua própria empresa, principalmente ao levantar as informações do plano de contas. Neste contexto se perguntou os principais fatores que fizeram com que a decisão de não movimentar a organização. Observe a tabela 4.

Tabela 4: Decisão manter sem movimentação e o desejo recomeçar

O que pesou na decisão de parar com a empresa

Especificações

A empresa não estava dando retorno financeiro

questão familiar

mudança para outro estado/município

\begin{tabular}{|l|l|}
\hline Freq & $\%$ \\
\hline 19 & $25 \%$ \\
\hline 25 & $33 \%$ \\
\hline 26 & $35 \%$ \\
\hline
\end{tabular}




\begin{tabular}{|l|l|l|}
\hline Não tenho mais interesse pela organização & 5 & $7 \%$ \\
\hline Total & $\mathbf{7 5}$ & $\mathbf{1 0 0 \%}$ \\
\hline Empresário, você tem a intenção de retornar com a organização & & \\
\hline Especificações & Freq & $\%$ \\
\hline SIM & 52 & $69 \%$ \\
\hline NÃO & 23 & $31 \%$ \\
\hline Total & $\mathbf{7 5}$ & $\mathbf{1 0 0 \%}$ \\
\hline & & \\
\hline
\end{tabular}

Fonte: Elaborada pelas Autora. Questionário. 2019.

Os dados demonstram que as mudanças para outro estado ou município foi a que mais motivou a situação de cancelamento empresarial. Nesse ponto muitos dos empresários indagaram que a movimentação dos processos nos órgãos públicos ainda é difíceis e os serviços contábeis. Segundo Oliveira, Müller e Nakamura (2000) entendem que a justificativa para esta realidade se dá pela influência e medo fiscal, e que tendem a permitir distorções relevantes nas informações contábeis, produzindo as demonstrações contábeis legais de difícil compreensão. A partir destas características da informação contábil, assumida pela assimetria de informação, as quais confirmam a relevância da informação contábil tanto nos escritórios como para os empresários (PADOVEZE, 2015).

\section{CONSIDERAÇÕES FINAIS}

A dificuldade de ser manter uma organização no município estudado envolveram diversas questões desde a questão de mudança de local, como a falta do retorno financeiro desejado. Diante dessa perspectiva, entende-se que das informações da empresa e da própria formalização para se manter uma organização contribuem para os resultados atuais de altos índices de empresas com o status de canceladas, evidenciadas na pesquisa de campo, as quais aconteceram por meio de aplicações de questionários aos escritórios de contabilidade da cidade de Capanema - PA, haja vista que, diante das necessidades de obter informações, tornaram-se necessárias, principalmente para permitir solucionar a questão de pesquisa, permitindo identificar e analisar todas as respostas obtidas dos empresários (ARAÚJO; CRUZ, 2018). 
As maiores dificuldades encontradas para organizar essas manifestações de dados são provenientes da interpretação das perguntas e dos termos que são manifestados dentro da questão em que se busca conhecer ou descobrir. Conclui-se que o fator cultural, pode ser muito difícil para conseguir manter uma organização ou padronizar com sucesso um processo isolado, pois existem muitos fatores que impactam com maior veemência. Além disso os fatores ligados ao cancelamento empresarial não podem ser considerados um fator isolado, mas deve ser colocado a um conjunto de fatores internos e externos, sendo os fatores relacionados ao ambiente externo serem os principais causadores do cancelamento de seus negócios. Por fim, espera-se que os resultados que venham a ser alcançados todas as metas propostas da pesquisa desenvolvidas por este projeto (ARAÚJO; CRUZ, 2018).

\section{REFERÊNCIAS}

AATR - BA. Programa Juristas Leigos. Disponível em: http://www.dhnet.org.br/dados/cursos/aatr/a_pdf/06_aatr_direito_do_trabalho.pdf. Acesso em: 04. out. 2019.

ALBUQUERQUE, A. F. Fatores de mortalidade de pequenas empresas: análise de empresas do setor varejista a partir do ciclo de vida organizacional. 2013. 339 p. Tese (Doutorado) - Programa de Pós-Graduação em Engenharia de Produção. Escola de Engenharia de São Carlos. Universidade de São Paulo, São Carlos, 2013.

ALBUQUERQUE, A. F.; ESCRIVÃO FILHO, E. Fatores de Mortalidade de Pequenas Empresas: uma Análise da Produção Acadêmica no Período 2000-2010. In: V Encontro de Estudos em Estratégia. 2011. Porto Alegre, RS, Anais. 2011.

ARAÚJO, J. C. O; CRUZ, L. D. C. Informação incompleta ou imperfeita: um estudo sobre a informação contábil nos escritórios de contabilidade de Capanema - Pará. In: XV Congresso USP de Iniciação Científica em Contabilidade, 2018.

BRASIL. Lei Complementar (LC) № 123, de 14 de dezembro de 2006, que institui o Estatuto Nacional da Microempresa e da Empresa de Pequeno Porte. Capturado em: 
http://www.planalto.gov.br/ccivil_03/LEIS/LCP/Lcp123.htm. Acesso em: 04. Out. 2019.

BRASIL. LEI COMPLEMENTAR № 155, DE 27 DE OUTUBRO DE 2016. Altera a Lei Complementar $n^{\circ} 123$, de 14 de dezembro de 2006, para reorganizar e simplificar a metodologia de apuração do imposto devido por optantes pelo Simples Nacional; altera as Leis $n^{\text {os }} 9.613$, de 3 de março de 1998, 12.512, de 14 de outubro de 2011, e 7.998, de 11 de janeiro de 1990; e revoga dispositivo da Lei $n^{\circ} 8.212$, de 24 de julho de 1991. 2016.

CATELLI, Armando. (Coord.) Controladoria - Uma abordagem da Gestão Econômica - GECON. 2. ed. São Paulo: Atlas, 2001.

COUTO, M. H. G. et. al. Mortalidade Precoce das Micro e Pequenas Empresas: estudo das principais causas de falência empresarial em Bambuí/MG. Revista da Micro e Pequena Empresa, v. 11, n. 3, p. 39-53, 2017.

DIAS; J. C. R. As características qualitativas da informação contábil no desenvolvimento do controle social: uma análise da percepção dos conselheiros municipais do Recife sobre a utilidade das informações contábeis. 2011. Dissertação (Mestrado). Programa de Pós-Graduação em Ciências Contábeis, Universidade Federal de Pernambuco, Recife, 2011.

DORNELAS, J. C. A. Empreendedorismo: transformando ideias em negócios. $2^{\underline{a}}$ Ed. Rio de Janeiro: Elsevier, 2005.

FILARDI, L. F. et al. Análise quantitativa sobre a mortalidade precoce de micro e pequenas empresas da cidade de São Paulo. Revista Gest. Prod., v. 19, n.4, p.811823, 2012.

GIL, A. de L. Sistemas de Informações Contábil/Financeiros. 3ª ed. São Paulo: Atlas, 1999. 
Healy, P. M; Palepu, K. G. Information asymmetry, corporate disclosure, and the capital markets: a review of empirical disclosure literature. Journal of Accounting and Economics, v.31, p. 405-440, 2001.

IBPT. Instituto Brasileiro de Planejamento e Tributação. Causas de desaparecimento das micro e pequenas empresas. 2013.

LEZANA, A. G. R; GRAPEGGIA, M. Diagnóstico da fase do ciclo de vida organizacional. Revista Produção Online, Florianópolis, SC, v. 6, n. 3, 2006.

OLIVEIRA, A. G; MULLER, A. N; NAKAMURA, W. T. A utilização das informações geradas pelo sistema de informação contábil como subsídio aos processos administrativos nas pequenas empresas. Revista da FAE, v. 3, n.3, 2000.

PADOVEZE, C. L. Controladoria Estratégica e Operacional. $3^{\text {a }}$ ed. rev. e atual. São Paulo: Cengage Learning, 2015.

PADOVEZE, C. L. Sistemas de Informações Contábeis. São Paulo: Atlas, 2009.

PORTER, M. The five Competitive Forces that shape Strategy. 2008. Disponível em: http://www.fae.edu/publicacoes/pdf/revista_da_fae/f. Acesso em: 01. Out. 2019.

REGIÃO INTEGRAÇÃO, Região do Caeté. Online. Disponível em : http://www.fcp.pa.gov.br/regioes-e-municipios/regiao-rio-caete. Acesso em: 15. out. 2017.

RIBEIRO, A; FREIRE, E. J; BARELLA, L. A. A informação contábil como instrumento de apoio às micro e pequenas empresas: percepção dos gestores de micro e pequenas empresas de Paranaíta-MT, quanto à utilização de informações da contabilidade no processo de tomada de decisão. 2012.

SEBRAE. Fatores Condicionantes e Taxas de Sobrevivência e Mortalidade das Micro e Pequenas Empresas no Brasil 2003-2005. 2017. 
SEBRAE. Os donos de negócio no Brasil, por regiões e por unidades da federação: série de estudos e pesquisas. 2015.

SHANE, S.; VENKATARAMAN, S. The promise of entrepreneurship as a field of research. Academy of Management Review, v. 25. n. 1. p. 217-226, jan. 2000.

Enviado: Setembro, 2019.

Aprovado: Outubro, 2019. 